\title{
Emissions of selected gas pollutants in the application of the additive Envirox ${ }^{\mathrm{TM}}$
}

\author{
F. Bozek ${ }^{1}$, J. Mares ${ }^{1}$, H. Gavendova ${ }^{1} \&$ J. Huzlik ${ }^{2}$ \\ ${ }^{1}$ Civil Protection Department, University of Defence, Czech Republic \\ ${ }^{2}$ Transport Research Centre, Czech Republic
}

\begin{abstract}
The value of selected emission factors was monitored in the operation of an older type of engine testing bench using diesel and compared with the same parameters monitored under similar conditions with the addition of the additive, Envirox ${ }^{\mathrm{TM}}$. It was found that the additive based on $\mathrm{CeO}_{2}$ nanoparticles reduces emissions of hydrocarbons $\mathrm{C}_{\mathrm{x}} \mathrm{H}_{\mathrm{y}}$, and $\mathrm{NO}_{\mathrm{x}}$, while emissions of $\mathrm{CO}_{2}$ remain comparable or slightly lower and $\mathrm{CO}$ emissions even significantly increase. Dependence of tested emissions on reduced torque $T M_{R}$, engine power $P$ and revolutions $f$ was observed as well.

Keywords: additive, emission factor, nano-particle, environment, cerium dioxide, carbon mono-oxide, nitrogen oxide.
\end{abstract}

\section{Introduction}

Escalating activities of human society in order to ensure a higher standard of living brings along a number of negative externalities. Among the important, and by the lay and professional community strongly discussed externalities, belongs the increase of burden to the atmosphere through the implementation of industrial and agricultural activities, energy production, waste management and household management. To the increase in ambient air pollution also contributes a significant level of mobile assets, consisting primarily of passenger and goods transport [1].

It is estimated that transport contributes to overall air pollution by carbon monoxide (CO) and carbon dioxide $\left(\mathrm{CO}_{2}\right)$ emissions by $37 \%$, a mixture of nitrogen oxide and nitrogen dioxide $\left(\mathrm{NO}_{\mathrm{x}}\right)$ by $30 \%$, and volatile organic compounds (VOCs), about $24 \%$. Besides the above, the quantitative aspect of the 
dominant pollutant is the traffic which is also producer of other, mainly health and eco highly harmful substances [2]. Emitted pollutants have often nonquantifiable impact on morbidity and mortality of the population, ecosystem function and value of social assets [3].

Because transportation is currently one of the world's most dynamically developing sectors, it is necessary, in accordance with the principles of sustainable development, to pay enormous attention to minimize emissions. This requirement is compounded by the use of personal automobiles at the expense of public transport and permanently increasing the ratio of road haulage transport relative to rail transport [1].

The submitted paper is devoted to the evaluation of the quantities of $\mathrm{CO}_{2}, \mathrm{CO}$, $\mathrm{NO}_{\mathrm{x}}$ and VOCs in the form of unburned hydrocarbons $\mathrm{C}_{\mathrm{x}} \mathrm{H}_{\mathrm{y}}$ emissions from fuels used in conventional diesel engines in comparison to the addition of fuel additive based on cerium dioxide $\left(\mathrm{CeO}_{2}\right)$.

\section{The analysis of current state}

The amount of pollutants emitted while driving a motor vehicle is dependent on many factors. If the typical way of driving for each driver is left aside, as well as the nature of terrain and weather conditions, the current emissions are dependent upon, in particular:

a) The type of engine and its technical parameters [4];

b) Principles of oxidation catalyst effect [5];

c) The type and amount of biodiesel added to the base fuel [6];

d) The composition and quality of used motor oil [7];

e) The type and composition of additives added to the basic fuel [8].

The calculation of the $i$-th pollutant emission is based on the knowledge of an emission factor $E f_{m}^{i}\left[\mathrm{~g} \mathrm{~kg}^{-1}\right]$ which is consistently with eqn (1) given by weight of the $i$-th pollutant per a unit mass of consumed fuel [9]:

$$
E f_{m}^{i}=m_{i} \times m_{F}^{-1}=y_{i}^{d} \times \frac{M_{i} \times n^{d}}{M_{F} \times N_{F}}
$$

where $m_{i}[\mathrm{~g}]$ is the mass of the $i$-th pollutant, $m_{F}[\mathrm{~kg}]$ weight of fuel, $M_{i}$ molar molecular weight of the $i$-th pollutant $\left[\mathrm{g} \mathrm{mol}^{-1}\right], M_{F}\left[\mathrm{~kg} \mathrm{~mol}^{-1}\right]$ molar molecular weight of fuel, $n^{d}[\mathrm{~mol}]$ substance amount of dry exhaust gas, $N_{F}$ [mol] substance amount of consumed fuel, and finally $y_{i}^{d}$ molar fraction of the $i$-th pollutant in dry exhaust gasses.

The industry producing and supplying fuels operates with a number of additives that can be added to the diesel fuel. These can be divided into three main areas depending on their nature [10]:

a) Refinery additives;

b) Safety increasing or legally required additives;

c) Additives for improvement of technical parameters and increase of fuel performance. 


$$
\begin{gathered}
(8 \mathrm{x}+2 \mathrm{y}) \mathrm{CeO}_{2}+2 \mathrm{C}_{\mathrm{x}} \mathrm{H}_{\mathrm{y}}=(4 \mathrm{x}+\mathrm{y}) \mathrm{Ce}_{2} \mathrm{O}_{3}+2 \mathrm{x} \mathrm{CO}_{2}+\mathrm{y} \mathrm{H}_{2} \mathrm{O} \\
4 \mathrm{CeO}_{2}+\mathrm{C}=2 \mathrm{Ce}_{2} \mathrm{O}_{3}+\mathrm{CO}_{2} . \\
2 \mathrm{CeO}_{2}+\mathrm{CO}=\mathrm{Ce}_{2} \mathrm{O}_{3}+\mathrm{CO}_{2} \\
2 \mathrm{Ce}_{2} \mathrm{O}_{3}+2 \mathrm{NO}=4 \mathrm{CeO}_{2}+\mathrm{N}_{2} \\
4 \mathrm{Ce}_{2} \mathrm{O}_{3}+2 \mathrm{NO}_{2}=8 \mathrm{CeO}_{2}+\mathrm{N}_{2}
\end{gathered}
$$

$\mathrm{CeO}_{2}$ regeneration catalyst is carried out in accordance with chemical formula (7).

$$
2 \mathrm{Ce}_{2} \mathrm{O}_{3}+\mathrm{O}_{2}=4 \mathrm{CeO}_{2}
$$

Statistically validated operational tests carried out by Oxonica Company provide evidence that the recommended dosage of 5 to $10 \mathrm{ppm} \mathrm{w} / \mathrm{w} \mathrm{CeO}_{2}$ can achieve relevant reductions in fuel consumption (about 5-12\%) present reduction of emissions of $\mathrm{CO}_{2}, \mathrm{CO}, \mathrm{NO}_{\mathrm{x}}, \mathrm{C}_{\mathrm{x}} \mathrm{H}_{\mathrm{y}}$ and particulate matters. The additive is also compatible with all diesel common additives $[11,12]$.

\section{Problem solution}

\subsection{Applied methods and devices}

Tests to determine emission levels were carried out on the engine testing bench of VOP-026 Šternberk electric eddy current brake Schenk $0900 \mathrm{~kW}$, operating in the range of 0-6000 revolutions $\min ^{-1}$. Diesel NM-54 was used as the primary fuel which served as an alternative version for the comparative tests mixed with $2.5 \times 10^{-4}$ volumes of additives. The concentrations of $\mathrm{CeO}_{2}$ found in diesel fuel by inductively coupled plasma atomic emission spectroscopy was $7.6 \mathrm{ppm} w / \mathrm{w}$ which corresponds to Envirox ${ }^{\mathrm{TM}}$ suppliers' requirement.

For the actual test a diesel engine was used, four stroke, naturally-aspirated engine Tatra T3 930-31 with direct injection, air-cooled, engine cylinder capacity of $1.9 \times 10^{4} \mathrm{~cm}^{3}$, cylinder diameter/stroke $120 / 140 \mathrm{~mm}$, OHV distribution and a compression ratio of 1:16. The engine had 12 cylinders in two separate lines at $90^{\circ}$. Rated engine output was $235 \mathrm{~kW} \pm 10 \%$ at $2.2 \times 10^{3} \mathrm{~min}^{-1}$ with a maximum torque of $1.13 \times 10^{3} \mathrm{~N} \mathrm{~m}$ at revolutions $1.4 \times 10^{3} \pm 200 \mathrm{~min}^{-1}$.

Emission testing was performed by a combined device for analysis of combustion gas composition ECOM - JN, equipped by electrochemical sensor of an English company City Technology which enabled the determination of $\mathrm{CO}$, $\mathrm{NO}, \mathrm{NO}_{2}$ and $\mathrm{O}_{2}$ concentrations. Sensor types, ranges and uncertainty in determination of individual quantities are listed in table 1.

A sample of combustion gas was taken by a vacuum pump tube probe analyzer. The current air mass was led from the probe tube by unheated tube to filters and water separators analyzer and then to each pollutant sensors. It was possible to determine the concentration of $\mathrm{CO}$ and NOx by applying unheated tube between the probe and analyzer as possible combustion gas condensation in the traffic route did not affect their value. 
Table 1: $\quad$ Ranges and uncertainties in determination of measured quantities.

\begin{tabular}{|c|c|c|c|}
\hline \multirow{2}{*}{ Pollutant } & \multirow{2}{*}{$\begin{array}{c}\text { Range } \\
(\mathrm{ppm})\end{array}$} & \multicolumn{2}{|c|}{ Uncertainty of measurements } \\
\cline { 3 - 4 } & $0-2.0 \times 10^{3}$ & $20 \%$ range & $100 \%$ range \\
\hline $\mathrm{NO}$ & $0-2.0 \times 10^{2}$ & $2 \%$ & $5 \%$ \\
\hline $\mathrm{NO}_{2}$ & $0-1.0 \times 10^{4}$ & $2 \%$ & $5 \%$ \\
\hline $\mathrm{CO}$ & $0-2.1 \times 10^{5}$ & $2 \%$ & $5 \%$ \\
\hline $\mathrm{O}_{2}$ & 0 & $5 \%$ \\
\hline
\end{tabular}

CxHy content was tested by analyzer operating on the principle of flame ionization (FID). The principle uses the effect that the burning of hydrocarbons in the hydrogen flame of the combustion chamber of the analyzer burner gets ionized bond $\mathrm{C}-\mathrm{H}$. If the electrodes placed in the burner are energized, the value of flowing current is proportional to the number of free ions including organic matter content in the sample. Into the FID unit was the sample of gases transported through a tube heated vacuum pump analyzer.

Location of measuring point where the combustion gas velocity was measured with the Prandtl probe simultaneously with gas temperature measured with thermocouple is evident from fig. 1.

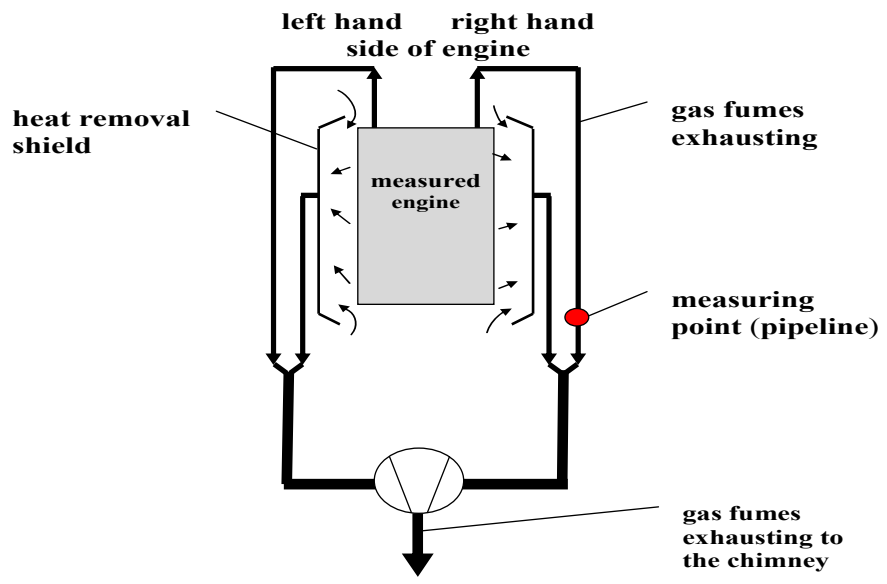

Figure 1: $\quad$ Location of sampling probes.

\subsection{Outcomes and discussion}

\subsubsection{Mass balance}

Calculation of emission factors was based on eqn (8) characterizing the combustion of fuel, also based on the carbon material balance, eqn (9), hydrogen (10), oxygen (11) and nitrogen (12), on the amount of substance entering into the combustion process $N_{V}^{d}[\mathrm{~mol}]$ and on the process 
of exiting $n^{d}$ [mol] of the dry gas. eqn (13) eventually (14) and finally based on measurements of the concentration of contaminants and oxygen. Fuel combustion in the engine was considered under simplified conditions in the absence of trace amounts of polycyclic aromatic hydrocarbons, $\mathrm{N}_{2} \mathrm{O}, \mathrm{NH}_{3}$, $\mathrm{SO}_{2}$ etc.

$$
\begin{gathered}
\mathrm{e} / 2 \mathrm{~N}_{2}+\mathrm{C}_{\mathrm{a}} \mathrm{H}_{\mathrm{b}} \mathrm{O}_{\mathrm{c}}+[\mathrm{a} \times(1-\mathrm{z} / 2)+\mathrm{b} / 4-\mathrm{c} / 2+\mathrm{d} \times(1-\mathrm{w} / 2)] \mathrm{O}_{2}= \\
=\mathrm{a} \times(1-\mathrm{z}) \mathrm{CO}_{2}+\mathrm{a} \times \mathrm{z} \mathrm{CO}+(\mathrm{b} / 2) \mathrm{H}_{2} \mathrm{O}+\mathrm{d} \times(1-\mathrm{w}) \mathrm{NO}_{2}+\mathrm{e} \times \mathrm{w} \mathrm{NO} \\
a \times\left(N_{F}-n_{F}\right)=n_{C O_{2}}+n_{\mathrm{CO}} \\
b \times\left(N_{F}-n_{F}\right)=2 n_{\mathrm{H}_{2} \mathrm{O}} \\
2\left(N_{\mathrm{O}_{2}}-n_{\mathrm{O}_{2}}\right)+c \times\left(N_{F}-n_{F}\right)=n_{\mathrm{H}_{2} \mathrm{O}}+2 n_{\mathrm{CO}_{2}}+n_{\mathrm{CO}}+2 n_{\mathrm{NO}_{2}}+n_{\mathrm{NO}} \\
2\left(N_{N_{2}}-n_{\mathrm{N}_{2}}\right)=n_{\mathrm{NO}_{2}}+n_{\mathrm{NO}} \\
N_{V}^{d}=N_{N_{2}}+N_{\mathrm{O}_{2}}+N_{\mathrm{CO}_{2}} \\
n^{d}=n_{\mathrm{N}_{2}}+n_{\mathrm{O}_{2}}+N_{\mathrm{CO}_{2}}+n_{\mathrm{CO}_{2}}+n_{\mathrm{CO}}+n_{F}+n_{\mathrm{NO}_{2}}+n_{\mathrm{NO}}
\end{gathered}
$$

In eqns (9)-(14) $N$ [mol] with the corresponding subscript represents amount of substance in the process of entering gases $\mathrm{N}_{2}, \mathrm{O}_{2}$ and $\mathrm{CO}_{2}$ and $n$ [mol] subscript represents amount of substance in the process of exiting exhaust gases, i.e. $\mathrm{N}_{2}, \mathrm{O}_{2}, \mathrm{CO}_{2}, \mathrm{CO}, \mathrm{NO}_{2}, \mathrm{NO}$ and fuels $F$.

To simplify the record of other formulas a substitution (15) was introduced where symbols $a, b$, c are stoichiometric coefficients in eqn (8).

$$
\omega=\frac{b-2 c}{4 a}=\frac{\beta}{4}-\frac{\gamma}{2}
$$

Molar fractions $Y_{i}^{d}$ a $y_{i}^{d}$ of $i$-th component in dry inlet air or combustion gas are defined by relations (16) or (17):

$$
\begin{gathered}
Y_{i}^{d}=N_{i} \times\left(N_{V}^{d}\right)^{-1}, \\
y_{i}^{d}=n_{i} \times\left(n^{d}\right)^{-1}
\end{gathered}
$$

where $N_{i}$ [mol] is the amount of substance of $i$-th component in the inlet $n_{i}$ [mol] is the amount of substance of $i$-th component in output, symbol $N_{V}^{d}[\mathrm{~mol}]$ has the same meaning as in eqn (13) and the symbol $n^{d}$ [mol] as in eqn (14).

Based on the mass balance relations with the acceptance of relations (15)-(17) eqn (18) and (19) can be derived. These are needed to calculate emission factors for $i$-th pollutant. The meaning of symbols used in these eqns is in respect of previous signs in eqns (9)-(17). 


$$
\frac{n^{d}}{N_{F}}=\frac{a \times\left[1+\omega \times\left(1-Y_{O_{2}}^{d}\right)\right]}{Y_{O_{2}}^{d}-y_{O_{2}}^{d}+\left(1-Y_{O_{2}}^{d}\right) \times \frac{y_{C O}^{d}}{2}-\left(1-\frac{Y_{O_{2}}^{d}}{2}\right) \times y_{N O_{2}}^{d}-\frac{y_{N O}^{d}}{2}+\left[a \times(1+\omega)-(1+a \omega) \times Y_{O_{2}}^{d}\right] \times y_{F}^{d}}
$$

\subsubsection{Molar fraction of unmonitored components}

Because the concentration of water vapor and $\mathrm{CO}_{2}$ in combustion gases were not monitored, it was necessary to express the molar fractions from the mass balance. After adjustment formula (20) was obtained for the molar fraction of water and formula (21) for the molar fraction of carbon dioxide.

$$
\begin{aligned}
& n^{d}=N_{V}^{d} \times \frac{1+\omega \times\left(1-Y_{O_{2}}^{d}\right)}{1+\omega \times\left(1-y_{O_{2}}^{d}\right)-\frac{y_{C O}^{d}}{2}+(1-\omega) \times \frac{y_{N O_{2}}^{d}}{2}-\omega \times \frac{y_{N O}^{d}}{2}-(1+\omega) \times y_{F}^{d}} \\
& y_{H_{2} O}^{d}=\frac{\beta}{2} \times \frac{Y_{O_{2}}^{d}-y_{O_{2}}^{d}+\left(1-Y_{O_{2}}^{d}\right) \times \frac{y_{C O}^{d}}{2}-\left(1-\frac{Y_{O_{2}}^{d}}{2}\right) \times y_{N O_{2}}^{d}-\frac{y_{N O}^{d}}{2}-Y_{O_{2}}^{d} \times y_{F}^{d}}{1+\omega \times\left(1-Y_{O_{2}}^{d}\right)} \\
& y_{C_{2}}^{d}=\frac{Y_{O_{2}}^{d}-y_{O_{2}}^{d}-\left[\omega \times\left(1-Y_{O_{2}}^{d}\right)+\frac{1+Y_{O_{2}}^{d}}{2}\right] \times y_{C O}^{d}-\left(1-\frac{Y_{O_{2}}^{d}}{2}\right) \times y_{N O_{2}}^{d}-\frac{y_{N O}^{d}}{2}-Y_{O_{2}}^{d} \times y_{F}^{d}}{1+\omega \times\left(1-Y_{O_{2}}^{d}\right)}
\end{aligned}
$$

\subsubsection{Calculation of fuel composition}

Stoichiometric coefficients in eqn (8) can be determined if the relative proportion $\psi_{i}$ of each $i$-th fuel components is known. It is clear that relations (22) and (23) stand good:

$$
\begin{gathered}
\beta=\frac{\psi_{H} \times A_{C}}{\psi_{C} \times A_{H}} \\
\gamma=\frac{\psi_{O} \times A_{C}}{\psi_{C} \times A_{O}}
\end{gathered}
$$

It is obvious that the molecular weight of fuel $\mu_{F}$ related to one carbon atom is given by eqn (24):

$$
\mu_{F}=A_{C}+\beta \times A_{H}+\gamma \times A_{O}=100 \times A_{C} \times \psi_{C}^{-1}
$$

where $\psi_{C}, \psi_{H}$ and $\psi_{O}$ means a relative content of carbon, hydrogen and oxygen in the fuel, $A_{C}, A_{H}$ and $A_{O}\left[\mathrm{~g} \mathrm{~mol}^{-1}\right]$ corresponding molar atomic weights and constants $\beta$ and $\gamma$ have the same meaning as in eqn (15). 
Using eqn (22) and (23) was derived the formula (25) for constant $\gamma$ and after substitution into relation (15) the eqn (26) for constant $\omega$ :

$$
\begin{gathered}
\gamma=\frac{\psi_{O} \times\left(A_{C}+\beta \times A_{H}\right)}{\left(100-\psi_{O}\right) \times A_{O}} \\
\omega=\frac{\beta}{4}-\frac{\psi_{O} \times\left(A_{C}+\beta \times A_{H}\right)}{2 \times\left(100-\psi_{O}\right) \times A_{O}}
\end{gathered}
$$

After substituting from relations (22) and (23) into formula (24) applies for $\mu_{F}$ eqn (27) from where it is possible easy to directly express stoichiometric coefficients $a, b, c$ of eqn (8).

$$
\mu_{F}=\frac{M_{F}}{a}=\frac{100 \times\left(A_{C}+\beta \times A_{H}\right)}{100-\psi_{O}}
$$

\subsubsection{Calculation of emission factors}

Emission factors for the $i$-th contaminant were calculated according to eqn (28) which was obtained by substitution of $n^{d} \times\left(N_{F}\right)^{-1}$ from relation (18) in eqn (1) and by application of eqn (27) for $\mu_{\mathrm{F}}=M_{F} \times \mathrm{a}^{-1}$.

$$
E f_{m}^{i}=\frac{y_{i}^{d} \times \frac{M_{i}}{\mu_{F}} \times\left[1+\omega \times\left(1-Y_{O_{2}}^{d}\right)\right]}{Y_{O_{2}}^{d}-y_{O_{2}}^{d}+\left(1-Y_{O_{2}}^{d}\right) \times \frac{y_{C O}^{d}}{2}-\left(1-\frac{Y_{O_{2}}^{d}}{2}\right) \times y_{N O_{2}}^{d}-\frac{y_{N O}^{d}}{2}+\left[a \times(1+\omega)-(1+a \omega) \times Y_{O_{2}}^{d}\right] \times y_{F}^{d}}
$$

Calculated values of emission factors under varying conditions of engine operation in the use of diesel NM 54 with or without additives are presented in table 2. From there it is obvious that the application of additives compared to clear diesel fuel amounted total decrease in emissions of $\mathrm{C}_{\mathrm{x}} \mathrm{H}_{\mathrm{y}}$ about $12 \%$ and $\mathrm{NO}_{\mathrm{x}}$ emissions of about $8.5 \%$, while emissions of $\mathrm{CO}$ notably increased by approximately $22.5 \%$. Differences of emission factors of $\mathrm{CO}_{2}$ were for both alternatives statistically insignificant. Summary reduction of $\mathrm{CO}_{2}$ emissions after applying additives by about $0.3 \%$ roughly correlates with the slightly $(1.5 \%)$ reduced fuel consumption during the entire measurement. The actual value of fuel consumption depends on engine operating conditions. Fuel savings of a maximum about 3\% were observed in the application of additives when reduced torque $T M_{R} \in\langle 890 ; 1030\rangle \mathrm{N} \mathrm{m}$, engine power $P \in\langle 186 ; 214\rangle \mathrm{kW}$, and revolutions $f \in\langle 1800 ; 2200\rangle \mathrm{min}^{-1}$. Due to the significant increase in concentrations $\mathrm{CO}$ in the combustion products the carbon balance of the burnt process varies within the measurement errors.

Oxonica company, engaged in long-term tests in urban and suburban transport with an additive Envirox ${ }^{\mathrm{TM}}$, advertises, depending on operating conditions and type of engine in the application of an additive, reduction of $\mathrm{C}_{\mathrm{x}} \mathrm{H}_{\mathrm{y}}$ emissions within $6-14 \%, 1-7 \%$ of $\mathrm{CO}$ and $\mathrm{NO}_{\mathrm{x}}$ by $11 \%$. Reduction of $\mathrm{CO}_{2}$ 
Table 2: Parameters of the engine and emission factors for selected pollutants with and without additive.

\begin{tabular}{|c|c|c|c|c|c|c|c|c|c|c|c|}
\hline Test & ML & $f$ & $T M_{R}$ & $T_{C G}$ & $T_{E P}$ & $P$ & $F C$ & $E f_{m}^{C_{x} H_{y}}$ & $E f_{m}^{C O}$ & $E f_{m}^{N O_{x}}$ & $E f_{m}^{C O_{2}}$ \\
\hline No & [\%] & {$\left[\mathrm{min}^{-1}\right]$} & {$[\mathrm{N} \mathrm{m}]$} & {$[\mathrm{K}]$} & {$[\mathrm{K}]$} & {$[\mathrm{kW}]$} & {$\left[\mathrm{kg} \mathrm{kWh}^{-1}\right]$} & {$\left[\mathrm{g} \mathrm{kg}^{-1}\right]$} & {$\left[\mathrm{g} \mathrm{kg}^{-1}\right]$} & {$\left[\mathrm{g} \mathrm{kg}^{-1}\right]$} & {$\left[\mathrm{g} \mathrm{kg}^{-1}\right]$} \\
\hline \multicolumn{12}{|c|}{ NM-54 } \\
\hline 1 & 100.0 & 2200 & 891.0 & 793 & 853 & 205.3 & 0.244 & 2.38 & 23.01 & 49.80 & 3084 \\
\hline 2 & 100.0 & 1399 & 1100.0 & 769 & 828 & 161.2 & 0.213 & 2.17 & 24.45 & 31.86 & 3082 \\
\hline 3 & 60.1 & 1803 & 993.0 & 773 & 833 & 187.5 & 0.226 & 2.42 & 27.66 & 48.41 & 3076 \\
\hline 4 & 54.4 & 1799 & 821.6 & 663 & 720 & 154.8 & 0.220 & 2.89 & 26.40 & 56.63 & 3077 \\
\hline 5 & 50.0 & 1799 & 616.1 & 593 & 629 & 116.1 & 0.231 & 3.97 & 26.97 & 56.83 & 3073 \\
\hline 6 & 46.8 & 1800 & 408.4 & 527 & 550 & 77.0 & 0.264 & 5.64 & 28.78 & 51.43 & 3065 \\
\hline 7 & 100.0 & 2199 & 932.3 & 764 & 821 & 214.7 & 0.235 & 3.01 & 27.77 & 36.18 & 3074 \\
\hline \multicolumn{12}{|c|}{ NM-54 + Envirox ${ }^{\mathrm{TM}}$} \\
\hline 1 & 100.0 & 2201 & 927.8 & 780 & 840 & 213.8 & 0.236 & 4.63 & 48.98 & 41.81 & 3036 \\
\hline 2 & 100.0 & 1399 & 1109.2 & 771 & 836 & 162.5 & 0.214 & 3.29 & 35.01 & 34.60 & 3062 \\
\hline 3 & 63.4 & 1799 & 1022.3 & 767 & 826 & 192.6 & 0.219 & 2.01 & 26.62 & 43.21 & 3079 \\
\hline 4 & 57.2 & 1799 & 817.7 & 673 & 721 & 154.0 & 0.219 & 1.54 & 23.16 & 49.09 & 3086 \\
\hline 5 & 53.3 & 1801 & 616.3 & 595 & 633 & 116.2 & 0.227 & 1.90 & 22.98 & 47.81 & 3085 \\
\hline 6 & 50.3 & 1801 & 408.0 & 520 & 549 & 76.9 & 0.260 & 3.17 & 25.48 & 44.35 & 3077 \\
\hline 7 & 100.0 & 2201 & 934.6 & 772 & 832 & 215.4 & 0.233 & 3.25 & 45.17 & 45.81 & 3046 \\
\hline
\end{tabular}

emissions should be in accordance with a reduction in fuel consumption, which is declared by the company to be in an interval of 5-12\% [12].

$\mathrm{ML}[\%]$ motor load, $f\left[\mathrm{~min}^{-1}\right]$ engine revolutions, $T M_{R}[\mathrm{~N} \mathrm{~m}]$ reduced torque, $T_{C G}[\mathrm{~K}]$ temperature of combustion products, $T_{E P}$ temperature of exhaust pipe, $P[\mathrm{~kW}]$ engine power, $F C\left[\mathrm{~kg} \mathrm{kWh}^{-1}\right]$ fuel consumption, $E f_{m}{ }^{i}\left[\mathrm{~g} \mathrm{~kg}^{-1}\right]$ emission factor for the $i$-th contaminant.

Results obtained by us are in compliance with data reported by the Oxonica company solely for $\mathrm{C}_{\mathrm{x}} \mathrm{H}_{\mathrm{y}}$ and $\mathrm{NO}_{\mathrm{x}}$ emissions however for contaminants $\mathrm{CO}_{2}$ and $\mathrm{CO}$ are markedly different. The fact that there is no declared reduction of fuel consumption and hence reduction of $\mathrm{CO}_{2}$ and that $\mathrm{CO}$ emission factor even strongly increased may be partially explained by short-term sampling after the addition of Envirox ${ }^{\mathrm{TM}}$ into diesel fuel. Moreover, increased production of $\mathrm{CO}$ could have been caused by oxidation of carbon residue in the engine. Also it could have been caused by an older type of engine with production year 1986, in which the mentioned effect does not sufficiently appear. For these reasons, there are planned additional verification tests for the newer engine type with a sampling period of at least 200 engine hours of the engine operation with fuel containing the investigated additive.

At the same time the dependence of emission factor values were monitored as a function of $T M_{R}$ reduced torque, engine power $P$ and engine revolutions $f$. According to theoretical assumptions, the majority of emissions after an initial 
slight increase tend to decrease with increasing $T M_{R}$ and reach a minimum of around $180 \mathrm{~kW}$ engine power. The example in fig. 2 illustrates the graphical dependence of the emission factor values for $\mathrm{NO}_{\mathrm{x}}$ as a function of $T M_{R}$. Format of the trend line was evaluated by linear regression second degree polynomial with the corresponding regression equation with reliability value $\mathrm{R}$ and they are included within the graph. For yet unknown reasons the maximum of $\mathrm{CO}_{2}$ emissions was observed in engine power around $180 \mathrm{~kW}$, when the fuel consumption is on the minimal.

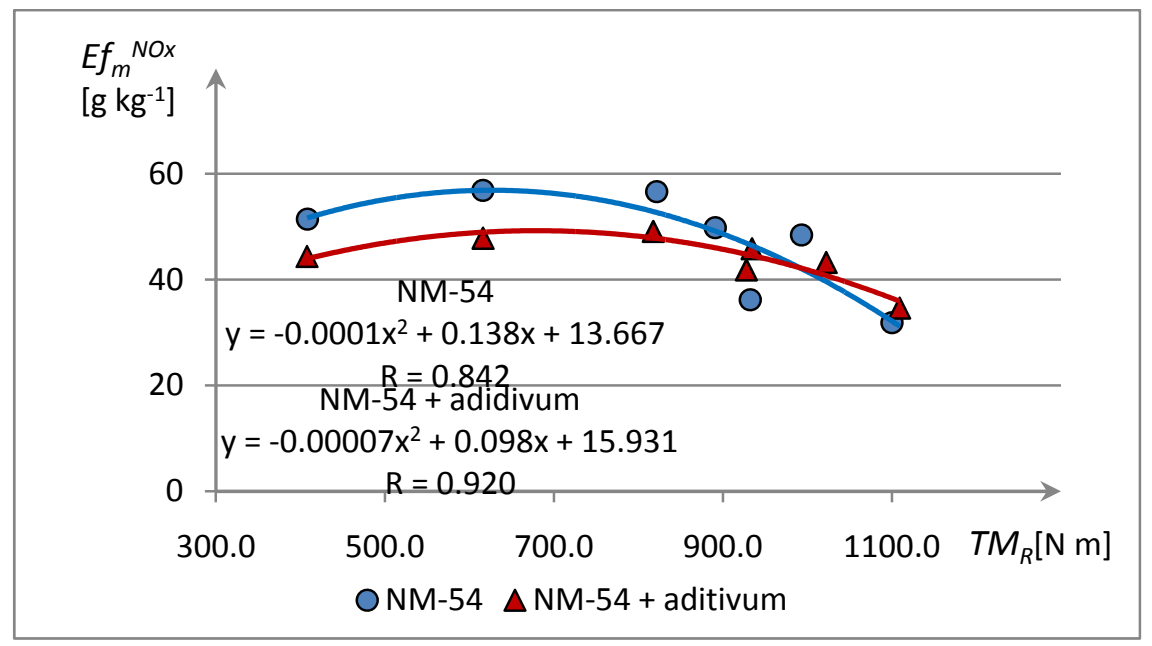

Figure 2: The dependence of emission factor $E f_{m}^{N O_{2}}$ on reduced torque $T M_{R}$ for both test alternatives.

Also decline in value of emission factors at the engine revolutions of $f \approx 1900 \mathrm{~min}^{-1}$ is consistent with the theory because these conditions lead to efficient use of fuel. In contrast to this theory is the growth in $\mathrm{CO}_{2}$ emissions when applying fuel additives, the increase in $\mathrm{C}_{\mathrm{x}} \mathrm{H}_{\mathrm{y}}$ emissions, if the clear diesel fuel was used and $\mathrm{NO}_{\mathrm{x}}$ emissions in both alternatives of test in discussed area of engine revolutions. Therefore it will be meaningful to verify these gaps with additional planned experiments under conditions listed above.

\section{Conclusions}

A methodology was developed for measuring and calculating emissions determination of $\mathrm{C}_{\mathrm{x}} \mathrm{H}_{\mathrm{y}}, \mathrm{NO}_{\mathrm{x}}, \mathrm{CO}$ and $\mathrm{CO}_{2}$ in the engine exhaust. With its use it was found that the additive Envirox ${ }^{\mathrm{TM}}$ based on dispersed nanoparticles of $\mathrm{CeO}_{2}$ reduces the value of emission factors for $\mathrm{C}_{\mathrm{x}} \mathrm{H}_{\mathrm{y}}$ by approximately $12 \%$ and $\mathrm{NO}_{\mathrm{x}}$ by around $8.5 \%$. Nevertheless the reduction of $\mathrm{CO}_{2}$ corresponding with lower fuel consumption in the range $5-12 \%$ declared by Oxonica company could not be established. Maximum fuel savings of about 3\% were found out only 
under optimum conditions of engine operation with a corresponding decrease in $\mathrm{CO}_{2}$ emissions by only circa $1 \%$. In contrast with announced lower amount of CO emissions an increase of almost $23 \%$ was observed.

At the same time was monitored dependence of emission factors on reduced torque, engine power and engine revolutions. With some exceptions the referred functions were in accordance with theoretical expectations.

The divergence between $\mathrm{CO}_{2}$ a $\mathrm{CO}$ emissions production and the data stated by Oxonica Company as well as data collected in some dependency of emission factors on selected engine characteristics will be necessary to verify with further tests on newer type of engine and after sufficiently long period of engine operation with the addition of Envirox ${ }^{\mathrm{TM}}$ fuel efficiency additive.

\section{References}

[1] Bozek, F. et al., Genotoxic Risk for Population in Vicinity of Traffic Communication Caused by PAHs Emissions, Proc. of the Conf. Transactions on Environment and Development, 6(3), pp. 186-195, 2010.

[2] Adamec, V. et al., Traffic, Health and Environment. Grada Publishing, a.s.: Prague, p. 58, 2008. ISBN 978-80-247-2156-9.

[3] Peters A. et al. Associations between Mortality and Air Pollution in Central Europe. Environ. Health Perspect. 108, pp. 283-287, 2000.

[4] Knecht, W. Diesel Engine Development in View of Reduced Emission Standards. Energy, 33(2), pp. 264-271, 2008.

[5] Clerc, J. C. Catalytic Diesel Exhaust After-treatment. Applied Catalysis B: Environmental, 10(1-3), pp. 99-115, 1996.

[6] Pandey, R. K. et al. Automobile Emission Reduction and Environmental Protection through Use of Green Renewable Fuel. Journal of Water, Energy and Environment, 7, pp. 65-70, 2010.

[7] Lappas, A. A. et. al. Production of Low Aromatics and Low Sulphur Diesel in a Hydrodesulphurization Pilot Plant Unit. Global Nest: the International Journal, 1(1), pp. 15-22, 1999.

[8] Gürü, M. et al. Improvement of Diesel Fuel Properties by Using Additives. Energy Conversion and Management, 43(8), pp. 1021-1025, 2002.

[9] Dzung, H. M., Thang, D. X. Estimation of Emission Factors of Air Pollutants from the Road Traffic in Ho Chi Minh City. Journal of Science, Earth Sciences, 24, pp. 184-192, 2008.

[10] Oxonica. Technical note 1. Diesel Fuel Additives and Envirox ${ }^{T M}$ Fuel Efficiency Additive. Oxford: Oxonica, p. 3, 2008.

[11] Wakefield, G. et al. Envirox ${ }^{\mathrm{TM}}$ Fuel-Borne Catalyst: Developing and Launching a Nano-Fuel Additive. Technology Analysis \& Strategic Management, 20(1), pp. 127-136, 2008.

[12] Attfield, M. Envirox TM Fuel-Borne Catalyst. Oxford: Oxonica, p. 49, 2009. 